\title{
Practice guideline: Idiopathic normal pressure hydrocephalus: Response to shunting and predictors of response
}

Report of the Guideline Development, Dissemination, and Implementation Subcommittee of the American Academy of Neurology

\section{０喵会}

John J. Halperin, MD Roger Kurlan, MD Jason M. Schwalb, MD Michael D. Cusimano, $\mathrm{MD}, \mathrm{PhD}, \mathrm{FRCSC}$ Gary Gronseth, MD David Gloss, MD

Correspondence to American Academy of Neurology: guidelines@aan.com
Supplemental data at Neurology.org

\section{ABSTRACT}

Objective: We evaluated evidence for utility of shunting in idiopathic normal pressure hydrocephalus (iNPH) and for predictors of shunting effectiveness.

Methods: We identified and classified relevant published studies according to 2004 and 2011 American Academy of Neurology methodology.

Results: Of 21 articles, we identified 3 Class I articles.

Conclusions: Shunting is possibly effective in iNPH (96\% chance subjective improvement, 83\% chance improvement on timed walk test at 6 months) (3 Class III). Serious adverse event risk was $11 \%$ (1 Class III). Predictors of success included elevated $\mathrm{R}_{\mathrm{o}}(1 \mathrm{Class}$ I, multiple Class II), impaired cerebral blood flow reactivity to acetazolamide (by SPECT) (1 Class I), and positive response to either external lumbar drainage (1 Class III) or repeated lumbar punctures. Age may not be a prognostic factor (1 Class II). Data are insufficient to judge efficacy of radionuclide cisternography or aqueductal flow measurement by MRI.

Recommendations: Clinicians may choose to offer shunting for subjective iNPH symptoms and gait (Level C). Because of significant adverse event risk, risks and benefits should be carefully weighed (Level B). Clinicians should inform patients with iNPH with elevated $\mathrm{R}_{\mathrm{o}}$ and their families that they have an increased chance of responding to shunting compared with those without such elevation (Level B). Clinicians may counsel patients with iNPH and their families that (1) positive response to external lumbar drainage or to repeated lumbar punctures increases the chance of response to shunting, and (2) increasing age does not decrease the chance of shunting being successful (both Level C). Neurology ${ }^{\circledR}$ 2015;85:2063-2071

\section{GLOSSARY}

AAN = American Academy of Neurology; $\mathbf{A D}=$ Alzheimer disease $\mathbf{A E}=$ adverse event $\mathbf{C B F}=$ cerebral blood flow; $\mathbf{C l}=$ confidence interval; CIBIC-Plus = Clinician Interview-Based Impression of Change, plus carer interview; $\mathbf{C M I}=$ comorbidity index; CSF-IT = CSF infusion test; ELD = external lumbar drainage; GRADE = Grading of Recommendations Assessment, Development and Evaluation; ICP = intracranial pressure; $\mathbf{N P H}=$ idiopathic normal pressure hydrocephalus; $\mathbf{L P}=$ lumbar puncture; $\mathbf{N P H}=$ normal pressure hydrocephalus; $\mathbf{T T}=$ tap test.

In 1965, Hakim and Adams ${ }^{1}$ first described normal pressure hydrocephalus (NPH) as a condition characterized by the clinical triad of gait disturbance, urinary incontinence, and memory impairment; the presence of normal CSF pressure on lumbar puncture (LP); the radiologic finding of enlarged cerebral ventricles; and improvement after ventricular shunting. One of the few available epidemiologic studies estimates the incidence in a Norwegian population to be $5.5 / 100,000 .^{2}$ The condition has been emphasized as a potentially reversible cause of dementia and impaired gait. The NPH syndrome Hakim and Adams ${ }^{1}$ described is now separated into idiopathic NPH (iNPH) and secondary $\mathrm{NPH},{ }^{3}$ with the latter typically arising from conditions such as subarachnoid hemorrhage or infectious meningitis. Ventricular shunting is considered the standard of care for patients with secondary NPH. ${ }^{4}$ Actual experience with ventricular shunting for iNPH, however, has been less straightforward, with review articles describing response to shunting as variable, short-lived, and unpredictable, and with significant risks., ${ }^{4,5} \mathrm{On}$ the basis of this information, we systematically reviewed the literature regarding the diagnosis and treatment of iNPH. We asked 2 questions:

From the Overlook Medical Center (J.J.H., R.K.), Atlantic Neuroscience Institute, Summit, NJ; Department of Neurosurgery (J.M.S., M.D.C.), Henry Ford Medical Group, West Bloomfield, MI; Division of Neurosurgery (M.D.C.), St. Michael's Hospital, University of Toronto, Canada; Department of Neurology (G.G.), University of Kansas Medical Center, Kansas City; and Department of Neurology (D.G.), Geisinger Medical Center, Danville, PA. The American Association of Neurological Surgeons and the Congress of Neurological Surgeons affirm the educational content of this document. Go to Neurology.org for full disclosures. Funding information and disclosures deemed relevant by the authors, if any, are provided at the end of the article. 
1. What is the efficacy of ventricular shunting for iNPH (therapeutic question)?

2. Are there reliable clinical or laboratory predictors of a successful outcome of shunting (prognostic question) (efficacy and successful outcome both defined as a persistent, objectively demonstrable, and clinically meaningful improvement after shunting)?

DESCRIPTION OF THE ANALYTIC PROCESS In November 2010, the American Academy of Neurology (AAN) Guideline Development, Dissemination, and Implementation Subcommittee (appendices e-1 and e-2 on the Neurology ${ }^{\circledR}$ Web site at Neurology.org) formed a panel of experts to develop this guideline according to the processes outlined in the 2004 AAN process manual, with 2 exceptions: we used the 2011 AAN process manual in our approach to developing conclusions and used the therapeutic classification of evidence scheme subsequently updated from the 2011 AAN process manual. ${ }^{6,7}$ We performed an initial search of MEDLINE, EMBASE, LILACS, and the Cochrane Database from 1980 to September 2012, limited to Englishlanguage publications, using the search terms ("normal pressure hydrocephalus" or "NPH" or "adult hydrocephalus syndrome" or "hydrocephalus") and ("shunting" or "treatment") and ("trial" or "outcome" or "predictors" or "response") and "neurosurgery." The search identified 438 citations. We performed an updated search of MEDLINE and Cochrane from 2012 to November 2013 using ("normal pressure hydrocephalus" or "NPH") and filtering manually with terms of initial search. Subsequent to this update, 2 additional relevant studies were published and are included. We excluded case reports, editorials, meta-analyses, review articles, duplicative reports, and articles regarding only secondary $\mathrm{NPH}$, including fewer than 10 patients with iNPH or suspected iNPH (as smaller numbers would lack statistical power), using no comparison group, or following patients for response to therapy for less than 3 months. At least 2 reviewers working independently of each other screened each of the remaining abstracts for relevance. If discordant conclusions could not be resolved by consensus, we included a third reviewer. Two panelists reviewed in detail the articles considered relevant to either of the questions, using pre-established criteria for relevance. This selection process yielded a total of 36 articles. Each article was classified according to the AAN's classification schemes for therapeutic (2011) and prognostic (2004) articles (see appendix e-3).6,7 Table e-1 presents studies rated above Class IV (with one exception).
Many included studies lacked generalizability because patients, while representing a typical clinical spectrum, were preselected for surgery on the basis of tests other than the ones being studied. In these studies, we upgraded or downgraded certain therapeutic and prognostic conclusions using the formal AAN-modified GRADE (Grading of Recommendations Assessment, Development and Evaluation) methodology (see tables e-2 and e-3). ${ }^{6,8}$ We linked recommendations directly to the evidence (see appendix e-4).

ANALYSIS OF EVIDENCE There were 3 Class I, 8 Class II, and 7 Class III studies relevant to the prognostic question. Three Class III studies were identified for the therapeutic question. All remaining articles had Class IV evidence.

What is the efficacy of ventricular shunting for iNPH? One prospective study with Class III evidence evaluated 75 patients with NPH (58 with iNPH): 54 who had a positive CSF infusion test (CSF-IT) or CSF tap test (TT) (see below) and 21 who had negative test results and served as a comparison group. ${ }^{5}$ Only those patients with a positive CSF-IT or CSF TT then underwent ventricular shunting. After 6 months of follow-up, 52 of 54 (96\%) shunted patients reported "a subjective impression of overall improvement" (yes/no; not further characterized) vs 19\% of those who did not undergo shunting (risk difference 0.77 , 95\% confidence interval [CI] 0.55-0.90). On objective testing, $83 \%$ of treated patients improved on a test of gait vs $24 \%$ of those not shunted (risk difference 0.59 , 95\% CI 0.36-0.83); 65\% improved on a measure of reaction time and $48 \%$ on a test of memory vs $46 \%$ and $28 \%$, respectively. Both the gait and subjective improvement were significant $(p=$ 0.0006 for both; Fisher exact test with Bonferroni correction). Only $43 \%$ of the shunted patients were available for testing 5 years after the operation (and $19 \%$ of nonoperated patients), which was attributed to unrelated mortality and a decline in general health. For shunted patients, measured response decreased, with $40 \%$ improved in gait and reaction time and $10 \%$ improved in memory; $56 \%$ reported ongoing subjective improvement compared with preoperative baseline. There were 3 subdural hematomas or effusions (5\%), one requiring surgical evacuation. There also was one shunt infection, one superficial wound infection, and one pulmonary embolism (1 Class III study). ${ }^{5}$

A second prospective, nonrandomized trial with Class III evidence ${ }^{9}$ evaluated 33 patients with suspected iNPH as determined by clinical symptoms, ventriculomegaly, and ventricular stasis on a radionuclide CSF flow study (injection of radioisotope into 
the lumbar subarachnoid space with serial imaging tracking ventricular entry and washout). All were offered shunt surgery, and 19 underwent surgery. Of the remainder, 4 were on a waiting list for surgery, and 10 declined surgery. These 14 controls were comparable with the patients who had the operation. Outcomes were assessed 3 to 4 months after surgery by an independent observer using the Clinician Interview-Based Impression of Change, plus carer interview (CIBIC-Plus), which assesses change in global ratings as well as cognitive, balance and gait, and urinary functioning. ${ }^{10}$ Among shunted patients, median CIBIC-Plus rating was 2 (moderate improvement) vs 6 (moderately worse) in controls ( $p<0.001$ for global ratings, Kruskal-Wallis test). On global ratings, 14 of 18 shunted patients showed marked or moderate improvement, one showed minimal worsening, and none demonstrated marked or moderate worsening, whereas 9 of 14 controls showed marked or moderate worsening ( $p=0.03$, Fisher exact test; relative risk $0.35,95 \%$ CI $0.13-0.83$ ). On gait measures, $89 \%$ of shunted patients showed moderate to marked improvement, a finding not occurring in controls.

A third prospective, randomized, nonblinded study ${ }^{11}$ using the modified Rankin Scale as an objective outcome measure (Class III) evaluated $93 \mathrm{pa}-$ tients with suspected $\mathrm{iNPH}$, at least 1 of the 3 clinical elements of the triad, and ventriculomegaly on imaging. Patients were randomized to undergo lumboperitoneal shunting within 1 month or 3 months of randomization. In the intention-to-treat analysis, 32 of 49 patients in the immediate group and 2 of 44 in the delayed group improved $\geq 1$ point on the modified Rankin Scale, assessed 3 months after randomization (difference 61\% [95\% CI $42 \%$ 68\%], $p<0.0001)$.

Conclusions. Shunting is possibly effective in patients with iNPH, with a $96 \%$ chance of subjective improvement and an $83 \%$ chance of improvement on the timed walk test at 6 months (3 Class III studies). The risk of serious adverse events (AEs) was 11\%. We upgraded the strength of evidence from very low to low because of the strong subjective effect of shunting, with $95 \%$ reporting subjective improvement in symptoms, compared with only $19 \%$ of controls. Among objective measures, only gait improved significantly.

Are there reliable clinical or laboratory predictors of successful outcome of shunting? In all studies, the authors considered patients candidates for inclusion if they had all or part of the clinical triad, brain imaging studies demonstrating ventriculomegaly, and no history of factors that could cause secondary hydrocephalus. In the absence of an objective reference standard for iNPH diagnosis, we used this combination of clinical and imaging findings, as summarized in the Japanese iNPH Guidelines and elsewhere, as a basis for the diagnosis. ${ }^{12,13}$

CSF dynamics and infusion tests. In addition to the clinical response to CSF removal, studies have investigated CSF dynamics. CSF flow is pulsatile-pressure fluctuates with arterial pressure and with B waves; the latter slow rhythmic oscillations in intracranial pressure (ICP) with periods of 30 to 120 seconds. ${ }^{14}$ A study of CSF drainage (Class IV for incorporation bias) and CSF dynamics (Class II) ${ }^{15}$ in 51 patients with iNPH found no relationship between B-wave amplitude or frequency and shunt response. Two small studies (1 Class $\mathrm{I}^{14}$ and 1 Class $\mathrm{II}^{16}$ ) did not show differences in $\mathrm{B}$ waves relating to shunt response, but they were underpowered to detect differences and are not considered further.

One Class I study, several Class II studies, and 1 Class III study considered a related but separate parameter, $R_{o}$. $R_{o}$ is a measure of outflow resistance during CSF-IT. It typically is calculated by taking the plateau CSF pressure minus the opening CSF pressure divided by the infusion rate: $\mathrm{R}_{\mathrm{o}}=\left(\mathrm{P}_{\mathrm{p}}-\mathrm{P}_{\mathrm{op}}\right) /$ infusion rate. In 1 Class I study ${ }^{17}$ of 142 patients with $i N P H$, in whom $R_{o}$ was measured preoperatively but whose results were concealed until final blinded outcome analysis (limited generalizability because of restricted spectrum of patients), there was no correlation between $R_{o}$ and outcome. However, this study found that at varying levels of $R_{o}$, applied to this population preselected on the basis of clinical and imaging criteria, positive predictive value could be as high as $94 \%$, but negative predictive value never exceeded $19 \%$. In one study ${ }^{18}$ of 17 patients diagnosed with iNPH (Class II) in whom $\mathrm{R}_{\mathrm{o}}>12 \mathrm{~mm}$ $\mathrm{Hg} / \mathrm{mL} / \mathrm{min}$, considered abnormal, was found in 14 , 2 patients with $\mathrm{R}_{\mathrm{o}}<12$ responded to shunting. Overall, $R_{o}$ was the only measured variable that predicted shunt response ( $p=0.007$ for gait improvement, $p=$ 0.022 for total NPH score) (table 1). In a multivariate logistic regression analysis of shunt response in 95 patients with $N P H,{ }^{19} R_{o} \geq 18$ was the only significant predictor of positive response (odds ratio for improvement on the NPH scale 4.39, 95\% CI 1.25-16.7). In a retrospective study of 55 patients shunted for NPH (40 with iNPH) (Class II but with limited generalizability because patients were selected on the basis of results of the CSF-IT) ${ }^{20}$ none of the CSF variables differed between shunt responders and nonresponders. Specifically, 16 patients with $\mathrm{R}_{\mathrm{o}}<18$ and 8 with $R_{o}<14$ responded well. However, patients were selected for surgery on the basis of either plateau pressure $>22 \mathrm{~mm} \mathrm{Hg}$ on the CSF-IT or a positive $T T$, and $R_{o}$ was found to correlate strongly with plateau pressure $\left(r^{2}=0.63\right)$. One Class III study also had a positive correlation. ${ }^{21}$ 
Table 1 Normal pressure hydrocephalus score used by a number of authors to quantify patients' limitations

$\begin{array}{lll}\text { Gait } & & \text { Urinary incontinence } \\ \text { Normal } & 5 & \text { None } \\ \text { Walk with support } & 4 & \text { Rare incontinence } \\ \text { Requires cane } & 3 & \text { Occasional incontinence } \\ \text { Support by person } & 2 & \text { Constant incontinence } \\ \text { Wheelchair or bed } & 1 & \text { Permanent catheter }\end{array}$

$\begin{array}{lll} & \text { Cognition } & \\ 5 & \text { None } & 6 \\ 4 & \text { Subjective decrease in memory } & 5 \\ 3 & \text { Objective decrease in memory but independent } & 4 \\ 1 & \text { Partial loss of independence } & 3 \\ & \text { Disoriented } \times 2 & 2 \\ & \text { Institutionalized secondary to dementia } & 1\end{array}$

Reprinted from the British Journal of Neurosurgery (Sorteberg A, Eide PK, Fremming AD. A prospective study on the clinical effect of surgical treatment of normal pressure hydrocephalus: the value of hydrodynamic evaluation. $\mathrm{Br} J \mathrm{Neuro}$ surg 2004;18:149-157), @ 2004, with permission from Informa Healthcare. ${ }^{18}$

Conclusion. In patients with suspected iNPH, those with elevated $R_{o}$ are probably more likely to respond to shunting than those without elevated $\mathrm{R}_{\mathrm{o}}$ (1 Class I study and multiple consistent Class II studies), but lower $\mathrm{R}_{\mathrm{o}}$ does not preclude shunt responsiveness.

Comorbidities. One study, ${ }^{22}$ Class II for the effect of demographics on shunt response, observed that in patients responding to external lumbar drainage (ELD), shunt response was independent of age (not an element in the comorbidity index [CMI]) up to the ninth decade.

A Class III study (previously discussed) ${ }^{21}$ created a CMI tabulating medical diagnoses (table 2). Of 64 patients with iNPH, those with scores $\leq 3$ had better responses $(p=0.003)$. Overall, $66 \%$ of patients with iNPH had a good response, but $83 \%$ of those with low CMI had a good response.

Conclusions. Age is possibly not an independent risk factor for poor shunt response (1 Class II study). In patients with suspected iNPH, there is insufficient evidence to determine whether those with 3 or more major comorbidities are likely to respond less favorably to shunting than those with fewer comorbidities (1 Class III study).

TT/ELD. In one study (Class III for spectrum bias), ${ }^{23} 19$ patients with iNPH underwent prolonged
ELD against a medium resistance valve followed by shunting. Improvement with ELD predicted shunt response. When gait was measured, 16 of 19 who improved with ELD improved with shunting; 1 of 3 who did not improve with ELD still improved with shunting. A Class I study ${ }^{17}$ (previously discussed) of 142 patients with iNPH, in whom TTs were performed preoperatively but whose results were concealed until final blinded outcome analysis (limited generalizability because of restricted spectrum of patients), found no correlation between results of the TT and outcome. However, this study found that in this population, preselected on the basis of clinical and imaging criteria, positive predictive value of the TT was $88 \%$ but negative predictive value only $18 \%$, resulting in an overall accuracy of 53\%.

Conclusion. In patients with suspected iNPH, there is insufficient high-quality evidence to conclude that improvement in response to ELD predicts response to shunting. Patients who improve after TTs may be more likely to respond to shunting, but negative TTs do not preclude a response to shunting.

Cerebral blood flow and acetazolamide reactivity by $T$ c scan. One Class I study of 162 patients (with limited generalizability because patients were selected for surgery on the basis of a TT and CT cisternography with

\begin{tabular}{|c|c|c|c|}
\hline \multirow[t]{2}{*}{ Table 2} & dity index & & \\
\hline & 1 point & 2 points & 3 points \\
\hline Vascular risk factors & Hypertension & Diabetes mellitus & \\
\hline $\begin{array}{l}\text { Peripheral vascular } \\
\text { occlusion }\end{array}$ & Aortofemoral bypass; stent; internal carotid artery stenosis & $\begin{array}{l}\text { Peripheral vascular } \\
\text { occlusion }\end{array}$ & \\
\hline $\begin{array}{l}\text { Cerebrovascular } \\
\text { disease }\end{array}$ & Posterior circulation insufficiency & $\begin{array}{l}\text { Vascular encephalopathy; } \\
\text { TIA; PRIND }\end{array}$ & $\begin{array}{l}\text { Cerebral } \\
\text { infarct }\end{array}$ \\
\hline Heart & $\begin{array}{l}\text { Arrhythmia; valvular disease; heart failure (coronal); stent; } \\
\text { aortocoronary bypass; infarction }\end{array}$ & & \\
\hline
\end{tabular}

Abbreviation: PRIND = prolonged reversible ischemic neurologic deficit.

Each mentioned symptom or disease has to be assigned according to the indicated parameter-values (1-3 points). The sum represents the individual comorbidity index.

Reprinted from Acta Neurochirurgica Supplement (Kiefer M, Eymann R, Steudel WI. Outcome predictors for normal-pressure hydrocephalus. Acta Neurochir Suppl 2006;96:364-367), @ 2004, with permission from Springer. ${ }^{21}$ 
iodinated contrast ${ }^{24}$ found that SPECT cerebral blood flow $(\mathrm{CBF})$ in responders was no different from $\mathrm{CBF}$ in controls or nonresponders. The study also found that CBF reactivity to acetazolamide was significantly impaired in responders compared with controls $(p<0.0025)$ and nonresponders $(p<0.005)$.

Conclusion. In patients with suspected iNPH, those with impaired $\mathrm{CBF}$ reactivity to acetazolamide are possibly more likely to respond to shunting than those without impaired CBF reactivity to acetazolamide (1 Class I study downgraded because of imprecision and lack of directness).

MRI aqueductal CSF flow. One Class II study and 3 Class III studies addressed MRI aqueductal CSF flow. In the Class II study, ${ }^{25} 49$ patients with suspected $\mathrm{NPH}$ were selected on the basis of clinical picture and brain imaging, supplemented with findings following a large-volume LP in 36. Shunting was followed by improved gait in $86 \%$, improved continence in $69 \%$, and improved cognitive function in $44 \%$. Elevated aqueductal flow rate did not predict the response of any aspect of function, although all patients with rates $>33 \mathrm{~mL} / \mathrm{min}$ did improve. CSF flow rates in the 5 patients who did not improve clinically after a TT were higher than in the patients who did improve after LP.

One Class III study ${ }^{26}$ reviewed 35 patients with suspected NPH. ICP was measured with an extradural monitor, and patients were stratified as follows: ICP $>12 \mathrm{~mm} \mathrm{Hg}$ (active hydrocephalus, $\mathrm{n}=15$ ), ICP $<12 \mathrm{~mm} \mathrm{Hg}$ but with abnormal pressure waves (compensated hydrocephalus, $\mathrm{n}=18$ ), and ICP $<12$ $\mathrm{mm} \mathrm{Hg}$ with no abnormal waves (brain atrophy, $\mathrm{n}=$ $2)$. Aqueductal flow was compared with that in a group of 27 healthy volunteers and expressed as flow velocity; values greater than approximately $10 \mathrm{~mm} / \mathrm{s}$ were considered elevated. Of 33 patients with active or compensated hydrocephalus, 29 had elevated velocities; 28 of these patients improved with shunting. Of the 4 with normal aqueductal velocity, 3 improved with shunting. Another Class III study ${ }^{27}$ included 61 patients with suspected NPH (41 ultimately with iNPH) who underwent TTs, CSF-ITs, and MRI and were selected for shunting on the basis of clinical picture, brain imaging, and $R_{0} \geq 13$ on CSF-IT. Using a cutoff flow rate of $24 \mathrm{~mL} / \mathrm{min}$ (lower than in the Class II study and not directly comparable to the velocity measure in the other Class III study ${ }^{26}$ ), MRI sensitivity was $46 \%$, and specificity was $95 \%$ for iNPH. A third study ${ }^{28}$ reviewed 38 patients with suspected NPH, stratifying aqueductal CSF stroke volume as low $(\leq 50 \mu \mathrm{L})$, medium $(51-$ $100 \mu \mathrm{L})$, and high $(\geq 101 \mu \mathrm{L})$. There was no relationship between this measure and shunt response.

Conclusion. Patients with suspected iNPH who have high-velocity aqueductal flow on MRI scan and an abnormal CSF-IT are possibly more likely to respond to shunting (1 Class II study and 2 Class III studies).

Neuropathology. One Class III cohort of 39 patients with iNPH ${ }^{29,30}$ using a composite NPH score assessing gait, cognition, and continence reported that patients with moderate to severe neuropathologic findings of Alzheimer disease (AD) were less likely to improve 2 or more points after shunting ( 2 of 8 ) than those with no Alzheimer pathology (6 of 8) $(p=$ $0.014)$. Elevated ventricular phosphorylated tau/ $A \beta 1-42$ ratios correlated with both $\mathrm{AD}$ and lumbar $\mathrm{CSF}$ ratios, suggesting this might be a predictive tool. ${ }^{29}$

Conclusion. In patients with suspected iNPH, there is insufficient evidence to determine whether those with moderate to severe neuropathologic findings of $\mathrm{AD}$ are likely to respond less favorably to shunting than those without Alzheimer pathology (1 Class III cohort).

Periventricular hyperintensities. A single Class II study ${ }^{31}$ examined whether periventricular hyperintensities were predictive of response. Formal statistics were not given, but Fisher exact test with Bonferroni correction of the result yields $p=0.12$. Using modified GRADE methodology, we downgraded this study to Class III because of an inability to detect differences.

Conclusion. There is insufficient evidence to determine whether the detection of periventricular hyperintensities on imaging is predictive of shunt response in patients with suspected iNPH (1 Class II study downgraded for lack of precision).

Radionuclide cisternography. There were no studies above Class IV examining this issue. ${ }^{31}$

Conclusion. There is insufficient evidence to determine whether patients with suspected iNPH and persistent ventricular stasis on radioisotope cisternography would respond to shunting (Class IV evidence only).

CLINICAL CONTEXT Because criteria for therapeutic questions are more restrictive than those used to assess prognostic issues, none of the studies cited in the therapeutic section provided high-level evidence of shunt efficacy. That said, it is worth noting (figure 1) that in other studies, more than $80 \%$ of patients shunted on the basis of results from TTs, ${ }^{31}$ $\mathrm{ELD}^{23}$ and CSF-ITs ${ }^{18,19}$ improved, just as in a cited therapeutic Class III study. ${ }^{5}$ Likewise, in studies of other diagnostic modalities ${ }^{26,27,30}$ in which patients were prescreened with TTs or CSF-ITs, overall response rate among all these patients (ignoring the results of the test under assessment) was approximately $80 \%$.

Numerous other studies report improvement of the majority of patients with iNPH after ventricular shunting, but none achieve a level of evidence of Class 
Figure 1 Percentage of patients improving with shunting in each of the 10 described studies

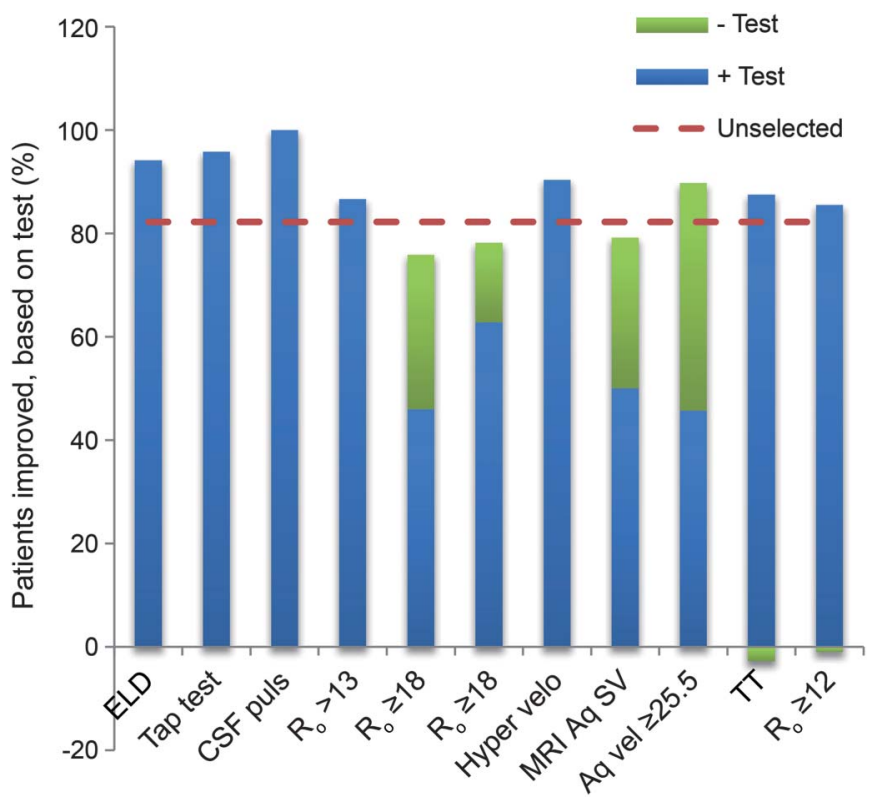

Summary of findings of included studies assessing different diagnostic testing modalities: external lumbar drainage (ELD; column $1^{23}$ ), tap test (TT; column $2^{31}$ ), CSF pulsatility (column $\left.3^{16}\right)$, CSF infusion tests measuring CSF flow resistance $\left(R_{0}\right.$; columns $4,{ }^{18} 5,{ }^{19}$ and $\left.6^{20}\right)$, aqueductal flow on MRI as measured by flow velocity (Hyper velo; column $7^{26}$ ), aqueductal stroke volume (Aq SV; column 828), aqueductal hypervelocity (Aq vel; column 9, ${ }^{27}$ defined as $\geq 25.5$ ), improvement after TT (column $10^{17}$ ), and $R_{\circ}<12$ on infusion test (column $11^{17}$ ). Each bar reflects the overall percentage of patients in that study judged to have improved after shunting. The horizontal dashed line represents the overall response rate among all studies. In all studies, all patients met clinical and brain imaging criteria for the diagnosis of idiopathic normal pressure hydrocephalus. In columns $1,{ }^{23} 2,{ }^{31} 3,{ }^{16} 4,^{18} 5,{ }^{19} 7,2610,,^{17}$ and $11,{ }^{17}$ patients were selected solely on the basis of these criteria. In columns $6,{ }^{20} 8,{ }^{28}$ and $9,{ }^{27}$ patients were additionally required to have a positive TT or CSF infusion test in order to undergo shunting. In the latter studies, substantial numbers of patients in whom the add-on investigational test was negative also responded to shunting. Hence, this figure shows the percentage responding among both test + and test - individuals.

III or better, generally because of absence of a comparison group, randomization, or blinded treatment or assessments. Many failed to identify a primary outcome measure. Some studies reported a reduction in complication rates with the use of programmable (adjustable-pressure) valves compared with fixedpressure valves..$^{32-34}$ Some studies also reported that the benefit of shunting declines over time. ${ }^{35-38}$

Comparing the prognostic impact of various techniques in the cited studies (figure 2) suggests that TTs, among the most widely used screening techniques, add little to sensitivity or specificity. However, this may be misleading because TTs and infusion tests were used to preselect patients for shunting both in the cited study ${ }^{31}$ and in many of the assessments of other modalities. As demonstrated in figure 2, TTs, ELD, and perhaps CSF pulsatility in response to arterial pressure appear to have high sensitivity with variable but incomplete specificity. $R_{o}$, measured in CSF-ITs in patients selected on the basis of only clinical and neuroimaging criteria, appears to add both sensitivity and specificity but still produces many false-negative results. Measuring aqueductal flow by MRI in patients preselected by TTs or infusion tests may provide some incremental improvement in sensitivity and specificity.

Assessment of comorbidities can enhance predictions of shunt responsiveness; however, the negative predictive value is limited, suggesting that these factors should be included among the considerations in decisions about shunting but should not be an absolute exclusion. Finally, although the presence of Alzheimer pathology unsurprisingly predicts a poor response to shunting, the morbidity associated with performing a brain biopsy before shunting would seem to outweigh the potential benefit. However, it will be worthwhile to study whether use of newer amyloid imaging techniques or measurement of CSF markers can serve as a useful surrogate.

Shunting is associated with significant cost and potential morbidity and mortality. One review found a pooled mean shunt complication rate of $38 \%$ and an overall combined rate of permanent neurologic deficit and death of $6 \% .^{4}$ Another publication reported mortality rates between $5 \%$ and $15 \%$ for the shunting procedure. ${ }^{39}$ In the recently reported SINPHONI multicenter trial (Class III), 22\% of shunted patients experienced significant AEs. ${ }^{11}$ In addition to the costs of hospitalization and surgery, patients with implanted shunts are at risk of shunt failure, ventriculitis, and shunt infections. The prolonged lumbar drainage diagnostic procedure is associated with a risk of meningitis and death of $1.8 \%-3.6 \%$ and $0.2 \%$, respectively. ${ }^{39,40}$ Several more recent studies describe complication rates of $15 \%{ }^{\mathrm{el}}$ to $28 \% \mathrm{e}^{\mathrm{e} 2}$

RECOMMENDATIONS Clinicians may choose to offer shunting as a treatment for patients with iNPH in order to treat their subjective symptoms of $\mathrm{iNPH}$ and gait (Level C). Because there is a risk of significant AEs, the risks and benefits of the procedure should be carefully weighed (Level B). Clinicians should inform patients with iNPH with elevated $\mathrm{R}_{\mathrm{o}}$ that they have an increased chance of responding to shunting compared with those without such elevation (Level B). Clinicians may counsel patients with iNPH that an abnormal CSF-IT or a positive response to repeated LPs increases the chance of response to shunting (Level C). Clinicians may counsel patients with iNPH and their families that increasing age does not necessarily decrease the chance of a shunt being successful (Level C). Clinicians may counsel patients with suspected $\mathrm{iNPH}$ and with impaired CBF reactivity to acetazolamide, measured by SPECT, that they are possibly more likely to respond to shunting (Level C). 
Figure 2 Receiver operating characteristic curve showing the incremental benefit of each of the discussed modalities

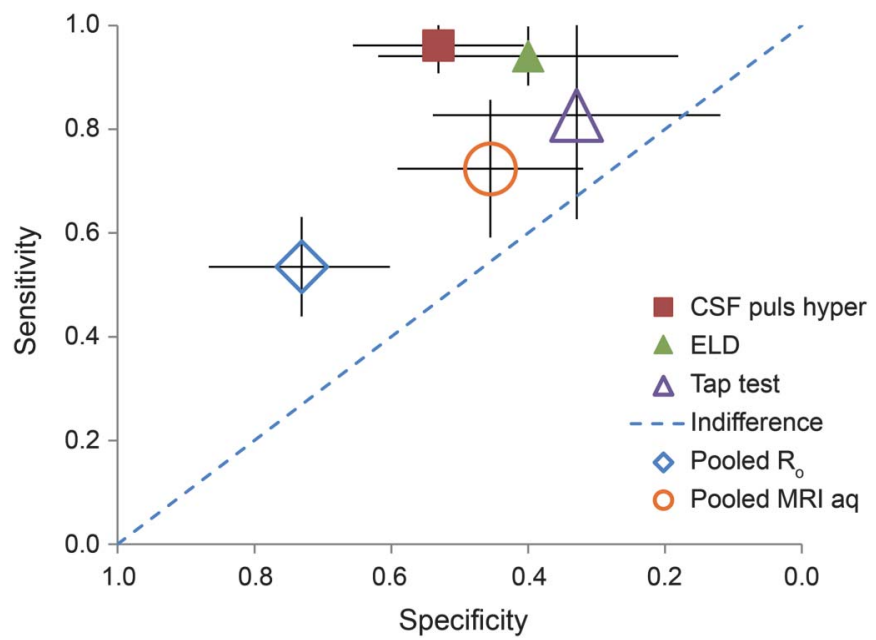

Measure of relative sensitivity and specificity of the different techniques described; studies are as listed in figure 1. Increased CSF pressure elevations in response to arterial pulsations ${ }^{16}$ are labeled CSF puls hyper. Results from studies in columns $4,{ }^{18} 5,{ }^{19} 6,{ }^{20}$ and $11^{17}$ of figure 1 were combined to provide a pooled assessment of $R_{0}$. Results from studies in columns $7,268,{ }^{28}$ and $9^{27}$ were combined to provide a pooled assessment of elevated CSF flow by MRI. Results from studies in columns $2^{31}$ and $10^{17}$ were combined to provide a pooled assessment of the CSF tap test. ELD = external lumbar drainage.

DISCUSSION What is the efficacy of ventricular shunting for iNPH? The 3 identified studies with higher than Class IV evidence suggest a benefit of ventricular shunting for iNPH, but there is a decrease of response after 6 months, ${ }^{5}$ and fewer than half of patients were considered to be improved in all presenting iNPH symptoms after 18 months. ${ }^{\text {e3 }}$ Although the vast majority of other published studies has reported clinical improvement of iNPH after ventricular shunting, none to date has been designed to provide high-level evidence of efficacy. It should be recognized that the use of ventricular shunting for iNPH is based largely on uncontrolled observational studies of clinical response.

If there is evidence of efficacy, are there clinical or laboratory predictors of a successful outcome? Clinicians have long recognized that at least some patients diagnosed with iNPH do not respond to ventricular shunting, leading to the publication of a large number of studies seeking to identify clinical or laboratory predictors of response. Our review identified only a small number of articles designed to provide high-level evidence in support of studied predictors. Differentiating between the effects of iNPH and AD is important but can be difficult. $\mathrm{AD}$ has been reported to coexist in patients with suspected iNPH. ${ }^{\mathrm{e}}{ }^{4}$ It is not surprising that the identification of Alzheimer pathology at the time of shunting would predict a poor outcome. There is evidence that improvement in gait following ELD, ${ }^{22}$ MRI-measured high CSF velocity through the aqueduct, ${ }^{26}$ and abnormal intracranial CSF hydrodynamics ${ }^{21}$ may predict a good response to shunting. It should be noted, however, that there have been publications of a lower evidence class indicating that these measures are not predictive. ${ }^{25, \mathrm{e} 5-\mathrm{e} 7}$ These procedures are associated with significant cost and potential complications, ${ }^{40}$ and, in the case of CSF-ITs, the equipment required is not widely available (particularly in the United States). A final determination of the value of predictors will depend on the establishment of shunting efficacy in welldesigned clinical trials.

\section{RECOMMENDATIONS FOR FUTURE RESEARCH} The question of the efficacy of ventricular shunting for iNPH is important, particularly because some recent reports describe disappointing response rates, failure to achieve long-lasting response, and substantial risks associated with shunting. ${ }^{4,5}$ Well-designed clinical trials of ventricular shunting in patients with iNPH are clearly needed, including a control intervention, randomized assignment, treatment masking, more objective outcome measures, and a sufficiently long observation period to document the duration of any benefit. Stratification of patients on the basis of possible $\mathrm{AD}$ using advanced neuroimaging or CSF markers may provide additional insights, as may consideration of other comorbidities and functional status.

The questions of diagnostic accuracy, prediction of response, and treatment efficacy are intertwined. It was estimated that 8,340 patients with iNPH underwent shunting in the United States from 2003 to 2009 e8 $^{\text {8 }}$ Because this procedure is frequently performed in countries such as the United States and newer types of shunts are more expensive, it is important to know whether shunting is effective. Properly performed studies of diagnosis, predictors, and treatment are essential.

\section{AUTHOR CONTRIBUTIONS}

John J. Halperin: study concept and design, acquisition of data, analysis or interpretation of data, drafting/revising the manuscript, critical revision of the manuscript for important intellectual content, study supervision. Roger Kurlan: study concept and design, acquisition of data, analysis or interpretation of data, drafting/revising the manuscript, critical revision of the manuscript for important intellectual content. Jason M. Schwalb: study concept and design, acquisition of data, analysis or interpretation of data, drafting/revising the manuscript. Michael D. Cusimano: study concept and design, acquisition of data, analysis or interpretation of data, drafting/revising the manuscript. Gary Gronseth: study concept and design, acquisition of data, analysis or interpretation of data, drafting/ revising the manuscript, critical revision of the manuscript for important intellectual content. David Gloss: analysis or interpretation of data, drafting/revising the manuscript, critical revision of the manuscript for important intellectual content.

\section{STUDY FUNDING}

This guideline was developed with financial support from the American Academy of Neurology. Authors who serve as AAN subcommittee 
members or methodologists (J.J.H., G.G., D.G.) were reimbursed by the AAN for expenses related to travel to subcommittee meetings where drafts of manuscripts were reviewed.

\section{DISCLOSURE}

J. Halperin serves on the editorial boards of The Neurologist and ACP Smart Medicine; serves on the Neurology journal Level of Evidence Review Team; has received honoraria for continuing medical education lectures; has received research support from the Centers for Disease Control and Prevention; and has given expert testimony and acted as witness or consultant regarding the defense of several physicians in medical malpractice cases. R. Kurlan serves as a supplement editor for Neurology; serves on the editorial board of Tremor and Other Hyperkinetic Movements; serves on the speakers bureau of Teva Pharmaceuticals; receives research support from the NIH, Kyowa, AstraZeneca, Rhythm, and Phytopharm; and served as a consultant on a medical malpractice case related to alleged missed diagnosis of normal pressure hydrocephalus (NPH). J. Schwalb serves on the Michigan Parkinson Foundation Physician and Epilepsy Foundation Physician Advisory Board; is a member of the American Association of Neurological Surgeons Subspecialty MOC Educational Materials and the Congress Quarterly editorial boards; has received honoraria from Medtronic; performs shunt placements for $\mathrm{NPH}$; and has received research support from the NIH and internal grants from the Henry Ford Health System Neuroscience Institute. M. Cusimano reports no disclosures relevant to the manuscript. G. Gronseth serves as an evidence-based medicine methodologist for the AAN and serves on the Neurology Level of Evidence editorial board. D. Gloss serves as an evidence-based medicine methodologist for the AAN and serves on the Neurology Level of Evidence editorial board. Go to Neurology.org for full disclosures.

\section{DISCLAIMER}

Clinical practice guidelines, practice advisories, systematic reviews, and other guidance published by the American Academy of Neurology (AAN) and its affiliates are assessments of current scientific and clinical information provided as an educational service. The information (1) should not be considered inclusive of all proper treatments, methods of care, or as a statement of the standard of care; (2) is not continually updated and may not reflect the most recent evidence (new evidence may emerge between the time information is developed and when it is published or read); (3) addresses only the question(s) specifically identified; (4) does not mandate any particular course of medical care; and (5) is not intended to substitute for the independent professional judgment of the treating provider, as the information does not account for individual variation among patients. In all cases, the selected course of action should be considered by the treating provider in the context of treating the individual patient. Use of the information is voluntary. The AAN provides this information on an "as is" basis and makes no warranty, expressed or implied, regarding the information. The AAN specifically disclaims any warranties of merchantability or fitness for a particular use or purpose. The AAN assumes no responsibility for any injury or damage to persons or property arising out of or related to any use of this information or for any errors or omissions.

\section{CONFLICT OF INTEREST}

The American Academy of Neurology (AAN) is committed to producing independent, critical, and truthful clinical practice guidelines (CPGs). Significant efforts are made to minimize the potential for conflicts of interest to influence the recommendations of this CPG. To the extent possible, the AAN keeps separate those who have a financial stake in the success or failure of the products appraised in the CPGs and the developers of the guidelines. Conflict of interest forms were obtained from all authors and reviewed by an oversight committee prior to project initiation. The AAN limits the participation of authors with substantial conflicts of interest. The AAN forbids commercial participation in, or funding of, guideline projects. Drafts of the guideline have been reviewed by at least 3 AAN committees, a network of neurologists, Neurology peer reviewers, and representatives from related fields. The AAN Guideline Author Conflict of Interest Policy can be viewed at www.aan.com. For complete information on this process, access the 2004 AAN process manual. ${ }^{6}$

Received April 06, 2015. Accepted in final form July 20, 2015.

\section{REFERENCES}

1. Hakim S, Adams RD. The special clinical problem of symptomatic hydrocephalus with normal cerebrospinal fluid pressure: observations on cerebrospinal fluid hydrodynamics. J Neurol Sci 1965;2:307-327.

2. Brean A, Eide PK. Prevalence of probable idiopathic normal pressure hydrocephalus in a Norwegian population. Acta Neurol Scand 2008;118:48-53.

3. Ishikawa M. Clinical guidelines for idiopathic normal pressure hydrocephalus. Neurol Med Chir 2004;44:222-223.

4. Hebb AO, Cusimano MD. Idiopathic normal pressure hydrocephalus: a systematic review of diagnosis and outcome. Neurosurgery 2001;49:1166-1184; discussion 1184-1186.

5. Kahlon B, Sjunnesson J, Rehncrona S. Long-term outcome in patients with suspected normal pressure hydrocephalus. Neurosurgery 2007;60:327-332; discussion 332.

6. American Academy of Neurology. Clinical Practice Guidelines Process Manual, $2004 \mathrm{ed}$. [online]. Available at: https:// www.aan.com/Guidelines/Home/UnderDevelopment. Accessed November 1, 2014.

7. American Academy of Neurology. Clinical Practice Guidelines Process Manual, 2011 ed. [online]. Available at: https://www.aan.com/Guidelines/Home/Development. Accessed November 1, 2011.

8. Guyatt GH, Oxman AD, Schunemann HJ, Tugwell P, Knottnerus A. GRADE guidelines: a new series of articles in the Journal of Clinical Epidemiology. J Clin Epidemiol 2011;64:380-382.

9. Razay G, Vreugdenhil A, Liddell J. A prospective study of ventriculo-peritoneal shunting for idiopathic normal pressure hydrocephalus. J Clin Neurosci 2009;16:1180-1183.

10. Knopman DS, Knapp MJ, Gracon SI, Davis CS. The Clinician Interview-Based Impression (CIBI): a clinician's global change rating scale in Alzheimer's disease. Neurology 1994;44:2315-2321.

11. Kazui H, Miyajima M, Mori E, Ishikawa M; SINPHONI-2 Investigators. Lumboperitoneal shunt surgery for idiopathic normal pressure hydrocephalus (SINPHONI-2): an open-label randomised trial. Lancet Neurol 2015;14: 585-594.

12. Ishikawa M, Hashimoto M, Kuwana N, et al. Guidelines for management of idiopathic normal pressure hydrocephalus. Neurol Med Chir 2008;48(suppl):S1-S23.

13. Relkin N, Marmarou A, Klinge P, Bergsneider $M$, Black PM. Diagnosing idiopathic normal-pressure hydrocephalus. Neurosurgery 2005;57:S4-S16; discussion ii-v.

14. Stephensen H, Andersson N, Eklund A, Malm J, Tisell M, Wikkelso C. Objective B wave analysis in 55 patients with non-communicating and communicating hydrocephalus. J Neurol Neurosurg Psychiatry 2005;76:965-970.

15. Woodworth GF, McGirt MJ, Williams MA, Rigamonti D. Cerebrospinal fluid drainage and dynamics in the diagnosis of normal pressure hydrocephalus. Neurosurgery 2009;64:919-925; discussion 925-926.

16. Foss T, Eide PK, Finset A. Intracranial pressure parameters in idiopathic normal pressure hydrocephalus patients with or without improvement of cognitive function after shunt treatment. Dement Geriatr Cogn Disord 2007;23:47-54. 
17. Wikkelso C, Hellstrom P, Klinge PM, Tans JT; European iNPH Multicentre Study Group. The European iNPH Multicentre Study on the predictive values of resistance to CSF outflow and the CSF tap test in patients with idiopathic normal pressure hydrocephalus. J Neurol Neurosurg Psychiatry 2013;84:562-568.

18. Sorteberg A, Eide PK, Fremming AD. A prospective study on the clinical effect of surgical treatment of normal pressure hydrocephalus: the value of hydrodynamic evaluation. Br J Neurosurg 2004;18:149-157.

19. Boon AJ, Tans JT, Delwel EJ, et al. The Dutch normalpressure hydrocephalus study. How to select patients for shunting? An analysis of four diagnostic criteria. Surg Neurol 2000;53:201-207.

20. Kahlon B, Sundbarg G, Rehncrona S. Lumbar infusion test in normal pressure hydrocephalus. Acta Neurol Scand 2005;111:379-384.

21. Kiefer M, Eymann R, Steudel WI. Outcome predictors for normal-pressure hydrocephalus. Acta Neurochir Suppl 2006;96:364-367.

22. Marmarou A, Young HF, Aygok GA, et al. Diagnosis and management of idiopathic normal-pressure hydrocephalus: a prospective study in 151 patients. J Neurosurg 2005; 102:987-997.

23. Panagiotopoulos V, Konstantinou D, Kalogeropoulos A, Maraziotis T. The predictive value of external continuous lumbar drainage, with cerebrospinal fluid outflow controlled by medium pressure valve, in normal pressure hydrocephalus. Acta Neurochir 2005;147:953-958; discussion 958.

24. Chang CC, Asada H, Mimura T, Suzuki S. A prospective study of cerebral blood flow and cerebrovascular reactivity to acetazolamide in 162 patients with idiopathic normalpressure hydrocephalus. J Neurosurg 2009;111:610-617.

25. Dixon GR, Friedman JA, Luetmer PH, et al. Use of cerebrospinal fluid flow rates measured by phase-contrast MR to predict outcome of ventriculoperitoneal shunting for idiopathic normal-pressure hydrocephalus. Mayo Clin Proc 2002;77:509-514.

26. Poca MA, Sahuquillo J, Busto M, et al. Agreement between CSF flow dynamics in MRI and ICP monitoring in the diagnosis of normal pressure hydrocephalus: sensitivity and specificity of CSF dynamics to predict outcome. Acta Neurochir Suppl 2002;81:7-10.

27. Al-Zain FT, Rademacher G, Meier U, Mutze S, Lemcke J. The role of cerebrospinal fluid flow study using phase contrast MR imaging in diagnosing idiopathic normal pressure hydrocephalus. Acta Neurochir Suppl 2008;102: 119-123.

28. Kahlon B, Annertz M, Stahlberg F, Rehncrona S. Is aqueductal stroke volume, measured with cine phase-contrast magnetic resonance imaging scans useful in predicting outcome of shunt surgery in suspected normal pressure hydrocephalus? Neurosurgery 2007;60:124-129; discussion 129-130.

29. Patel S, Lee EB, Xie SX, et al. Phosphorylated tau/amyloid beta $1-42$ ratio in ventricular cerebrospinal fluid reflects outcome in idiopathic normal pressure hydrocephalus. Fluids Barriers CNS 2012;9:7.

30. Hamilton R, Patel S, Lee EB, et al. Lack of shunt response in suspected idiopathic normal pressure hydrocephalus with Alzheimer disease pathology. Ann Neurol 2010;68: 535-540.

31. Kilic K, Czorny A, Auque J, Berkman Z. Predicting the outcome of shunt surgery in normal pressure hydrocephalus. J Clin Neurosci 2007;14:729-736.

32. Zemack G, Romner B. Adjustable valves in normalpressure hydrocephalus: a retrospective study of 218 patients. Neurosurgery 2002;51:1392-1400; discussion $1400-1402$.

33. Zemack G, Romner B. Seven years of clinical experience with the programmable Codman Hakim valve: a retrospective study of 583 patients. J Neurosurg 2000;92: 941-948.

34. Reinprecht A, Czech T, Dietrich W. Clinical experience with a new pressure-adjustable shunt valve. Acta Neurochir 1995;134:119-124.

35. Savolainen S, Hurskainen H, Paljarvi L, Alafuzoff I, Vapalahti M. Five-year outcome of normal pressure hydrocephalus with or without a shunt: predictive value of the clinical signs, neuropsychological evaluation and infusion test. Acta Neurochir 2002;144:515-523; discussion 523.

36. Malm J, Kristensen B, Stegmayr B, Fagerlund M, Koskinen LO. Three-year survival and functional outcome of patients with idiopathic adult hydrocephalus syndrome. Neurology 2000;55:576-578.

37. Raftopoulos C, Massager N, Baleriaux D, Deleval J, Clarysse S, Brotchi J. Prospective analysis by computed tomography and long-term outcome of 23 adult patients with chronic idiopathic hydrocephalus. Neurosurgery 1996;38:51-59.

38. Klinge P, Marmarou A, Bergsneider M, Relkin N, Black PM. Outcome of shunting in idiopathic normal-pressure hydrocephalus and the value of outcome assessment in shunted patients. Neurosurgery 2005;57:S40-S52; discussion ii-v.

39. Marmarou A, Black P, Bergsneider M, Klinge P, Relkin N. Guidelines for management of idiopathic normal pressure hydrocephalus: progress to date. Acta Neurochir Suppl 2005;95:237-240.

40. Greenberg BM, Williams MA. Infectious complications of temporary spinal catheter insertion for diagnosis of adult hydrocephalus and idiopathic intracranial hypertension. Neurosurgery 2008;62:431-435; discussion 435-436 


\section{Neurology}

Practice guideline: Idiopathic normal pressure hydrocephalus: Response to shunting and predictors of response: Report of the Guideline Development, Dissemination, and Implementation Subcommittee of the American Academy of Neurology John J. Halperin, Roger Kurlan, Jason M. Schwalb, et al. Neurology 2015;85;2063-2071

DOI 10.1212/WNL.0000000000002193

This information is current as of December 7, 2015

\section{Updated Information \&} Services

Supplementary Material

\section{References}

Citations

Errata

Permissions \& Licensing

Reprints including high resolution figures, can be found at: http://n.neurology.org/content/85/23/2063.full

Supplementary material can be found at: http://n.neurology.org/content/suppl/2015/12/05/WNL.0000000000002 193.DC1

http://n.neurology.org/content/supp1/2015/12/05/WNL.0000000000002 193.DC2

http://n.neurology.org/content/supp1/2016/07/20/WNL.0000000000002 193.DC3

http://n.neurology.org/content/suppl/2016/10/03/WNL.0000000000002 193.DC4

This article cites 38 articles, 4 of which you can access for free at: http://n.neurology.org/content/85/23/2063.full\#ref-list-1

This article has been cited by 6 HighWire-hosted articles: http://n.neurology.org/content/85/23/2063.full\#\#otherarticles

An erratum has been published regarding this article. Please see next page or: /content/86/8/793.full.pdf

Information about reproducing this article in parts (figures,tables) or in its entirety can be found online at:

http://www.neurology.org/about/about_the_journal\#permissions

Information about ordering reprints can be found online:

http://n.neurology.org/subscribers/advertise

Neurology ${ }^{\circledR}$ is the official journal of the American Academy of Neurology. Published continuously since 1951, it is now a weekly with 48 issues per year. Copyright @ 2015 American Academy of Neurology. All rights reserved. Print ISSN: 0028-3878. Online ISSN: 1526-632X.

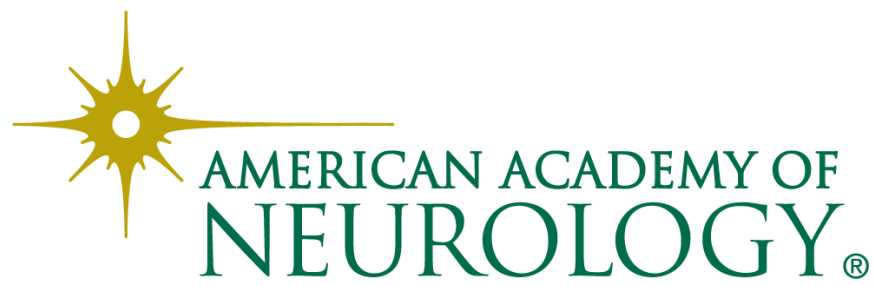


young age should not be used as a treatment indication.

Author Response: Nima Etminan, Mannheim, Germany; Akio Morita, Tokyo; Seppo Juvela, Helsinki: We thank Dr. Mayer for the comments on our recent article. ${ }^{1}$ As highlighted in the article, the proposed unruptured intracranial aneurysm (UIA) treatment score system requires further validation based on prospective data; this will commence shortly.

Due to the unique pathogenesis, natural history, and risk of treatment of UIAs, it is difficult to apply data from other entities (including arteriovenous malformations) to decide on the appropriate management of UIAs. ${ }^{4}$ There are data from prospective cohort studies on UIAs that can guide decisionmaking, but many uncertainties remain. ${ }^{5-7}$ This is complicated by lack of risk factor data for UIA treatment. Even though the quantities "natural history of UIAs" (a risk event rate) and "risk of treatment" (a one-time risk) cannot be directly compared, existing data suggest that preventive repair may be warranted if the cumulative lifelong risk of UIA rupture, including the annual discount rate for the remaining lifetime, outbalances the risk of UIA repair.

Thus, the disproportionate distribution of factors favoring treatment reflects the higher number of factors determining UIA rupture risks vs factors determining the one-time risk (preventive treatment). Despite the limitation of subgroup selection, recent data on the significant lifelong rupture risks of younger patients with UIA underline the necessity for a critical assessment of these patients. ${ }^{8}$

C) 2016 American Academy of Neurology

1. Etminan N, Brown RD Jr, Beseoglu K, et al. The unruptured intracranial aneurysm treatment score: a multidisciplinary consensus. Neurology 2015;85:881-889.

2. Raymond J, Darsaut TE, Molyneux AJ; TEAM collaborative Group. A trial on unruptured intracranial aneurysms (the TEAM trial): results, lessons from a failure and the necessity for clinical care trials. Trials 2011;12:64.

3. Mohr JP, Parides MK, Stapf C, et al; for the international ARUBA investigators. Medical management with or without interventional therapy for unruptured brain arteriovenous malformations (ARUBA): a multicentre, non-blinded, randomised trial. Lancet 2014;383:614-621.

4. Brown $\mathrm{RD} \mathrm{Jr}$, Broderick JP. Unruptured intracranial aneurysms: epidemiology, natural history, management options, and familial screening. Lancet Neurol 2014;13: 393-404.

5. Etminan N, Rinkel GJ. Cerebral aneurysms: cerebral aneurysm guidelines: more guidance needed. Nat Rev Neurol 2015;11:490-491.

6. Greving JP, Wermer MJ, Brown RD Jr, et al. Development of the PHASES score for prediction of risk of rupture of intracranial aneurysms: a pooled analysis of six prospective cohort studies. Lancet Neurol 2014;13:59-66.

7. Thompson BG, Brown RD Jr, Amin-Hanjani S, et al. Guidelines for the management of patients with unruptured intracranial aneurysms: a Guideline for Healthcare Professionals from the American Heart Association/American Stroke Association. Stroke 2015;46:2368-2400.

8. Korja M, Lehto H, Juvela S. Lifelong rupture risk of intracranial aneurysms depends on risk factors: a prospective Finnish cohort study. Stroke 2014;45:1958-1963.

\section{CORRECTION}

Practice Guideline: Idiopathic normal pressure hydrocephalus: Response to shunting and predictors of response: Report of the Guideline Development, Dissemination, and Implementation Subcommittee of the American Academy of Neurology

In the Practice Guideline "Idiopathic normal pressure hydrocephalus: Response to shunting and predictors of response" by J.J. Halperin et al. (Neurology 2015;85:2063-2071), there is an error in figure 1. The $\mathrm{R}_{\mathrm{o}}$ value on the $\mathrm{x}$-axis and in the sixth line of the figure legend should read $>12$, rather than $\geq 12$ and $<12$, respectively, as originally published. The authors regret the error. 